\title{
S-Nitrosylation of parkin as a novel regulator of p53-mediated neuronal cell death in sporadic Parkinson's disease
}

\author{
Carmen R Sunico ${ }^{1}$, Tomohiro Nakamura ${ }^{1}$, Edward Rockenstein ${ }^{2}$, Michael Mante ${ }^{2}$, Anthony Adame ${ }^{2}$, \\ Shing Fai Chan ${ }^{1}$, Traci Fang Newmeyer ${ }^{1}$, Eliezer Masliah ${ }^{2}$, Nobuki Nakanishi ${ }^{1}$ and Stuart A Lipton ${ }^{1,2^{*}}$
}

\begin{abstract}
Background: Mutations in the gene encoding parkin, a neuroprotective protein with dual functions as an E3 ubiquitin ligase and transcriptional repressor of p53, are linked to familial forms of Parkinson's disease (PD). We hypothesized that oxidative posttranslational modification of parkin by environmental toxins may contribute to sporadic PD.

Results: We first demonstrated that S-nitrosylation of parkin decreased its activity as a repressor of p53 gene expression, leading to upregulation of p53. Chromatin immunoprecipitation as well as gel-shift assays showed that parkin bound to the p53 promoter, and this binding was inhibited by S-nitrosylation of parkin. Additionally, nitrosative stress induced apoptosis in cells expressing parkin, and this death was, at least in part, dependent upon p53. In primary mesencephalic cultures, pesticide-induced apoptosis was prevented by inhibition of nitric oxide synthase (NOS). In a mouse model of pesticide-induced PD, both S-nitrosylated (SNO-)parkin and p53 protein levels were increased, while administration of a NOS inhibitor mitigated neuronal death in these mice. Moreover, the levels of SNO-parkin and p53 were simultaneously elevated in postmortem human PD brain compared to controls.

Conclusions: Taken together, our data indicate that S-nitrosylation of parkin, leading to p53-mediated neuronal cell death, contributes to the pathophysiology of sporadic PD.
\end{abstract}

Keywords: Nitric oxide (NO), S-nitrosylation, Parkin, p53, Nitrosative stress, Parkinson's disease

\section{Background}

Characterized by motor impairment and, with time, cognitive deficits, Parkinson's disease (PD) affects $\sim 1 \%$ of people over the age of 65 [1]. Histopathological features include loss of dopaminergic neurons, predominantly in the substantia nigra pars compacta, often accompanied by intracellular inclusions called Lewy bodies [2,3]. Rather than associated with a single gene mutation, more than $95 \%$ of PD cases are sporadic in nature, in some cases epidemiologically linked to pesticide exposure $[4,5]$. Although there are symptomatic treatments for PD

\footnotetext{
*Correspondence: slipton@sanfordburnham.org

${ }^{1}$ Sanford-Burnham Medical Research Institute, Del E. Webb Center for Neuroscience, Aging, and Stem Cell Research, 10901, North Torrey Pines Road, La Jolla, CA 92037, USA

${ }^{2}$ Department of Neurosciences and Pathology, University of California at San Diego, 9500, Gilman Drive, La Jolla, CA 92039, USA
}

patients, currently there is no effective therapy to prevent or cure this malady.

Mutations in the parkin gene have been associated with autosomal recessive juvenile PD and rare adult cases [6-9]. Parkin encodes an E3 ubiquitin ligase [9,10], and disruption in parkin-mediated protein ubiquitination may contribute in part to neuronal cell death [11-16], although other neuroprotective actions of parkin have also been reported $[17,18]$. In this regard, a novel role of parkin as a transcriptional repressor of p53 was recently demonstrated $[19,20]$.

Processes leading to progression of sporadic PD remain largely unknown. Several environmental stressors, including oxidative and nitrosative stress, have been epidemiologically linked to sporadic PD [21,22]. PD-linked environmental stressors may cause alterations in parkin solubility, promoting its aggregation and compromising

\section{Biomed Central}

(c) 2013 Sunico et al.; licensee BioMed Central Ltd. This is an Open Access article distributed under the terms of the Creative Commons Attribution License (http://creativecommons.org/licenses/by/2.0), which permits unrestricted use, distribution, and reproduction in any medium, provided the original work is properly cited. 
its protective function [23]. Additionally, oxidative or nitrosative stress can cause posttranslational modifications on parkin (sulfonation and S-nitrosylation, respectively) to disrupt its E3 ligase activity [24-26].

In the present study, we demonstrate that S-nitrosylation of parkin also decreased its activity as a repressor of p53 gene expression, and led to an upregulation of p53 mRNA and protein. Chromatin immunoprecipitation as well as gel-shift assays showed that parkin bound to the p53 promoter, and this binding was inhibited by the S-nitrosylation of parkin. Additionally, nitrosative stress, induced by pesticides that have been reported to be epidemiologically linked to $\mathrm{PD}$, induced SNO-parkin and cell death in a p53dependent manner in both cell-based and animal models. Administration of a NOS inhibitor mitigated the increase in SNO-parkin and p53 as well as neuronal cell death. Finally, in postmortem human PD brain, the levels of SNOparkin and p53 were increased in a correlative manner. Taken together, our data indicate that S-nitrosylation of parkin contributes to p53-mediated neuronal cell death, in part underlying the pathophysiology of sporadic PD.

\section{Results}

\section{Parkin is a negative regulator of p53}

Parkin has been reported to act as a transcriptional repressor of the p53 gene [20]. Initially, we confirmed this result by transiently expressing parkin in human embryonic kidney (HEK)-293 or human neuroblastoma SH-SY5Y cells and monitoring p53 promoter activity using a luciferase reporter assay. We found that parkin expression decreased p53 reporter gene activity in HEK-293 (Figure $1 A$ ) and SH-SY5Y (Figure $1 B$ ) cells by $16 \%$ and $22 \%$, respectively, compared to vector-transfected control cells. Additionally, we measured p53-promoter activity in an SH-SY5Y neuroblastoma cell line stably overexpressing parkin (ParkinSY5Y cells), and found that p53 promoter activity was decreased 68\% compared to the control (Figure 1C). For further analysis, we quantified the effect of parkin overexpression on p53 protein levels by immunoblotting. In cells transiently overexpressing parkin, p53 protein levels were decreased by $21 \%$ (Figure $1 D$ ), and in cells stably expressing parkin, p53 decreased by $91 \%$ (Figure $1 E$ ). These experiments confirmed that exogenously expressed parkin acts as a transcriptional repressor of p53 in these experimental systems.

\section{S-Nitrosylation of parkin reduces its ability to repress p53 gene expression}

We next asked whether S-nitrosylation of parkin affects its ability to repress p53 transcription. We initially used the neuroblastoma SH-SY5Y cells because the endogenous level of parkin expression is very low in this cell line (see Figure $1 D$ ), allowing us to easily identify the effect of parkin overexpression on activity. However, since parkin is not detectable in SH-SY5Y cells, this cell type cannot be used to assess the role of endogenous parkin in cell death occurring in Parkinson's disease.

We transiently transfected SH-SY5Y neuroblastoma cells with control pcDNA1 (pcDNA) or parkin-expression vector, together with a vector encoding the p53-reporter.
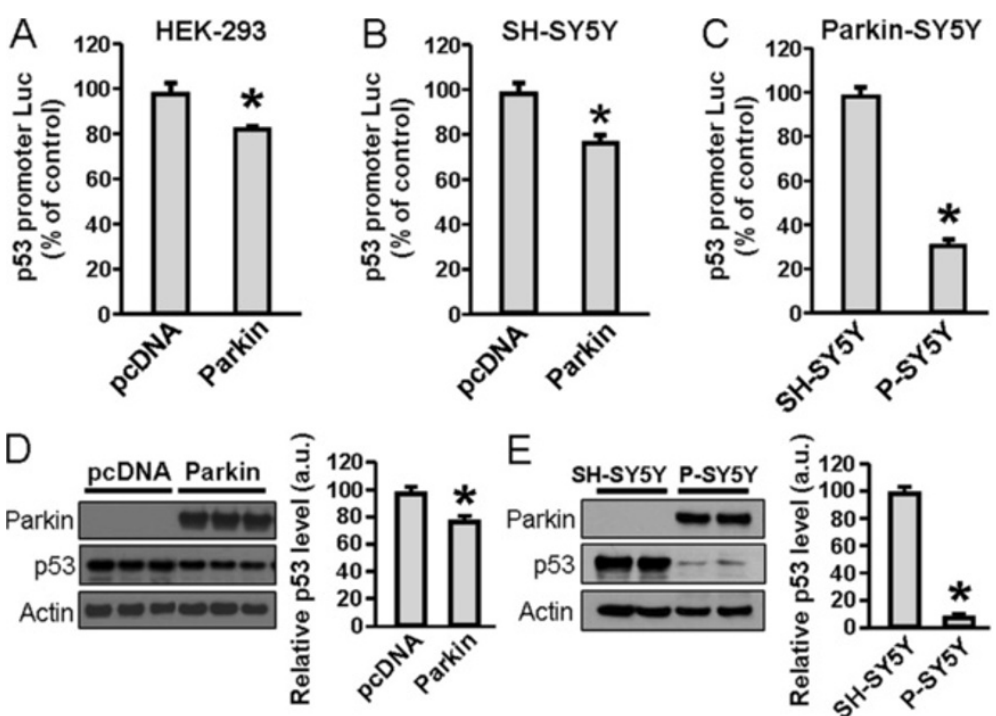

Figure 1 Parkin functions as a repressor of p53 transcription and protein levels. A-B, p53 promoter activity measured by luciferase assay in HEK-293 and SH-SY5Y cells transiently transfected with parkin or the control vector pcDNA. C, p53 promoter activity in SH-SY5Y cell line stably expressing parkin (P-SY5Y). D-E, Western blot analyses of parkin, p53 and actin in SH-SY5Y cells transiently (D) or stably (E) expressing parkin. Quantification of p53 signal (right panels) was made relative to actin and expressed in arbitrary units (a.u.). All values are mean + SEM, $n=6(\boldsymbol{A})$, 12 (B), 18 (C), 3 (D) and 9 (E); ${ }^{*} p<0.01$. 
Seventy-two hours after transfection, the cells were challenged with $200 \mu \mathrm{M}$ of the $\mathrm{NO}$ donor S-nitroso-glutathione (GSNO) for 6 hours. Using the biotin-switch technique, we found that parkin was S-nitrosylated under this condition (Figure 2B) [24,26].

Both with the pcDNA and parkin-expression vector, the cells exhibited higher levels of p53 promoter activity after GSNO exposure (Figure $2 A$ ), and the increase in p53 promoter activity was greater in cells expressing parkin than in control cells transfected with pcDNA. These data suggest that S-nitrosylation of parkin reduces the transcriptional repressor activity on the p53 gene. Furthermore, we performed immunoblotting and quantified the levels of p53 proteins in SH-SY5Y cells transfected with parkinexpression vector and subsequently exposed to GSNO. GSNO induced a significant increase in the $\mathrm{p} 53$ protein level in parkin-transfected SH-SY5Y neuroblastoma cells (Figure $2 B$ ). In summary, exogenous NO attenuated parkin-mediated repression of p53 transcription in SH-SY5Y cells.

\section{S-Nitrosylation alters nuclear localization of parkin and reduces its ability to bind to the p53 promoter}

For transcriptional repressor activity, parkin must be located in the nucleus in order to bind to DNA. It is thus possible that S-nitrosylation attenuates parkin function by altering nuclear localization of the protein. To test this notion, we examined the localization of parkin in cells exposed to S-nitrosocysteine (SNOC). We transiently transfected SH-SY5Y cells with myc-tagged parkin and exposed them to $200 \mu \mathrm{M}$ SNOC (or NO-dissipated control). Six hours later the cells were fixed, immunostained with anti-myc antibody, and stained with Hoechst. We found that parkin was localized in both the nucleus and cytoplasm in control-treated cells, while parkin was preferentially localized in the cytoplasm in cells exposed to SNOC (Figure $3 A$ ). These data indicate that S-nitrosylation of parkin leads to its exclusion from cell nuclei.

Using chromatin immunoprecipitation (ChIP), we studied the physical interaction between parkin protein and the p53 promoter sequence in SH-SY5Y cells. In cells overexpressing parkin compared to mock-transfected cells, we observed a significant increase in the level of parkin binding to the p53 promoter (Figure $3 B$ ). However, when we exposed these cells to $200 \mu \mathrm{M}$ GSNO, we could no longer detect a physical interaction between the two proteins (Figure $3 B$ ). These analyses suggest that $\mathrm{S}$-nitrosylation of parkin attenuates its ability to bind to the p53 promoter.

We also performed electrophoretic mobility shift assays (EMSAs) to monitor the physical interaction between parkin protein and the p53 promoter sequence in vitro. With increasing concentrations of recombinant parkin protein, we found an increase in the amount of shifted double-stranded oligonucleotide probe (Pp53) encoding the human p53 promoter (Figure 3C; left panels). Pre-incubation of parkin protein with $200 \mu \mathrm{M}$ 'old' SNOC for 10 minutes prior to the binding assay did not affect parkin-Pp53 interaction, while pre-incubation with $200 \mu \mathrm{M}$ SNOC significantly reduced the amount of mobility-shifted p53 promoter probe $(47 \%$ relative to old SNOC; Figure $3 C$ ). These data indicate that S-nitrosylation of parkin attenuates its ability to bind to the p53 promoter region.

\section{NO induces p53-dependent cell death in parkin- overexpressing cells}

We next asked whether S-nitrosylation of parkin contributes to p53-mediated neuronal cell death. To this end, we overexpressed parkin in SH-SY5Y cells and exposed them to a high concentration of the $\mathrm{NO}$ donor SNOC. In order to evaluate the involvement of p53 in this process, we performed gene silencing using a short

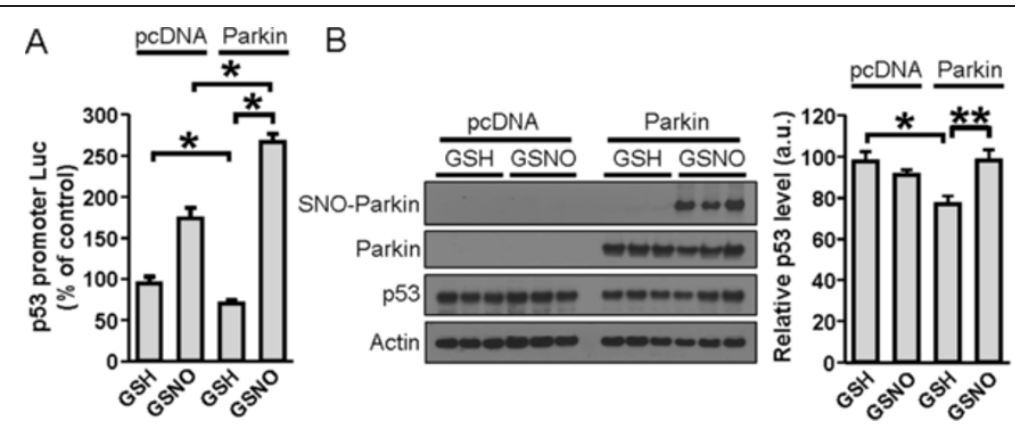

Figure 2 Effect of NO on p53 transcription and protein levels in parkin-overexpressing SH-SY5Y cells. $\boldsymbol{A}$, p53 promoter activity in cells transfected with the control (pcDNA) or Parkin-expression plasmid. The transfected cells were subsequently exposed to $200 \mathrm{\mu M}$ NO donor GSNO or the control compound GSH. Values are expressed as a percentage of the control (pcDNA-transfected GSH-treated cells). $\boldsymbol{B}$, Protein levels of parkin, p53 and actin by western blot (left panel) in cells transiently transfected with parkin or pcDNA, and exposed to 200 $\mu$ M GSNO or GSH. Quantification of p53 levels (right panel) was made relative to actin and expressed in arbitrary units (a.u.). Values are mean + SEM, $n=3$; ${ }^{*} p<0.01,{ }^{* *} p<0.05$. 

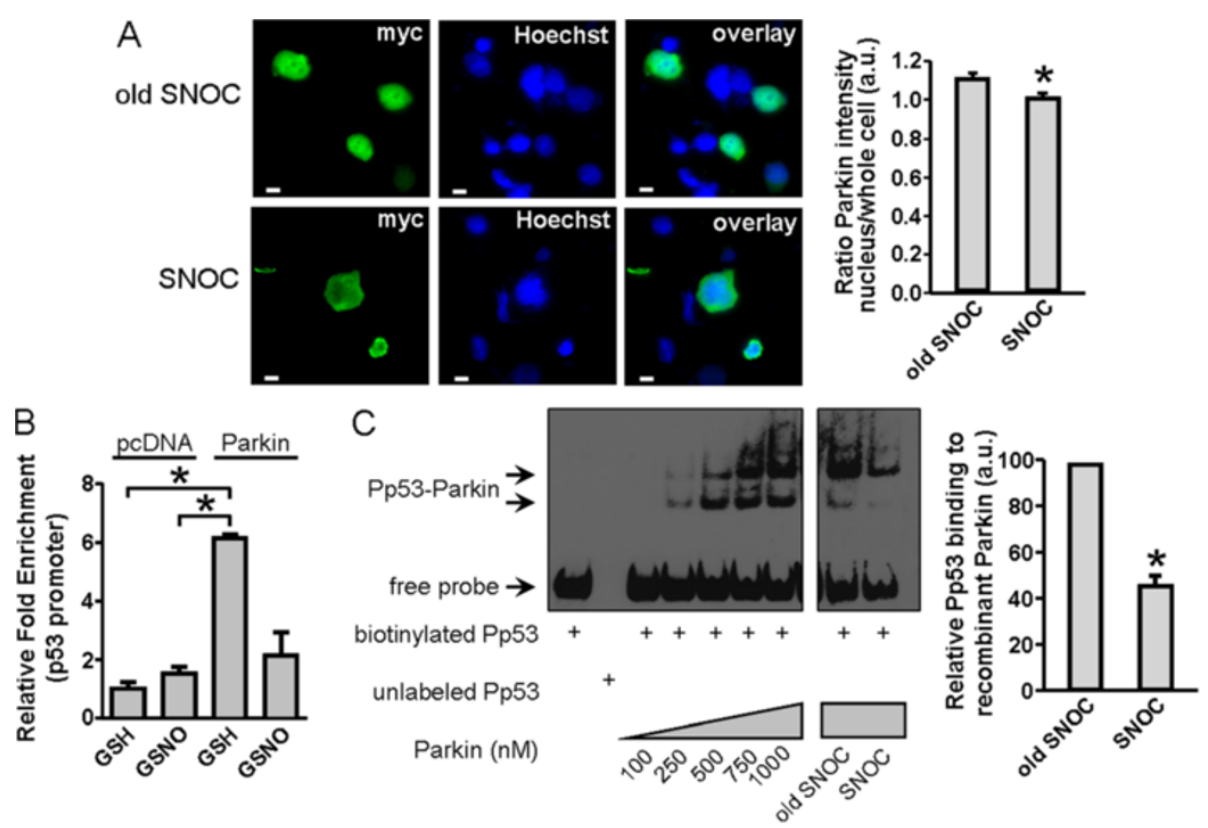

Figure 3 Effect of NO on subcellular localization of parkin and its physical interaction with p53 promoter (Pp53). $\boldsymbol{A}$, Histological images of SH-SY5Y cells transiently transfected with myc-tagged parkin and exposed to $200 \mu \mathrm{M}$ old or fresh SNOC. Cells were probed with anti-myc antibody (green) and Hoechst stain (blue). Quantification of the intensity ratio of parkin in the nucleus relative to cytoplasm (right panel) indicates that parkin is excluded from the nucleus after SNOC exposure. Scale bar: $10 \mu \mathrm{m}$. Values are mean + SEM, $n=9$ from triplicate experiments; ${ }^{*} p<0.01$. B , Chromatin immunoprecipitation (ChIP) assay using a specific parkin antibody (MAB5512) and oligonucleotide probe encoding the human p53 promoter sequence. Control or parkin-overexpressing SH-SY5Y cells were exposed to $200 \mu \mathrm{M}$ GSNO (or GSH) for 4 hours prior to performing the ChIP assay. Relative fold enrichment was assessed and normalized to control. Values are mean $+\mathrm{SEM}, n=4-5 ;{ }^{*} p<0.05$. C, Electrophoretic mobility shift assay (EMSA) using recombinant parkin protein and oligonucleotide probe encoding the human p53 promoter sequence. Parkin proteins were pre-exposed to $200 \mu \mathrm{M}$ old or fresh SNOC prior to incubation with the oligonucleotide probe. The optical density of shifted bands was quantified and expressed as percent control. Values are mean $+\mathrm{SEM}, n=4$; ${ }^{*} p<0.01$.

hairpin RNA that targets human p53 (p53-shRNA). By immunoblot analysis, transient expression of p53-shRNA reduced endogenous p53 protein levels by $65 \%$ (Figure $4 A$ ). Considering the fact that the transfection efficiency of p53-shRNA was $\sim 75 \%$, we concluded that p53-shRNA effectively knocked down endogenous p53.

Next, we transiently co-transfected SH-SY5Y cells with an expression vector encoding parkin cDNA together with the p53-shRNA vector (Figure $4 B$ ). As controls, pcDNA and non-targeting control (ctrl-) shRNA vectors were substituted for the parkin expression vector and p53-shRNA vector, respectively. shRNA vectors also encoded GFP to facilitate identification of transfected cells. After transfection, we exposed the cells to $600 \mu \mathrm{M}$ SNOC for 24 hours and then evaluated cell death by terminal-deoxynucleotidyl-transferase dUTP nick end labeling (TUNEL) assay. We scored the number of apoptotic cells as a percentage of total GFP-positive cells (Figure 4C). Firstly, transfection with the parkin plasmid reduced the number of apoptotic cells under all conditions examined, indicating that parkin overexpression was neuroprotective as expected based upon prior reports. Secondly, in cells transfected with control pcDNA, SNOC exposure induced apoptosis that was not inhibited by p53-shRNA transfection. In contrast, cells overexpressing parkin manifested SNOC-induced cell death that was significantly ameliorated by transfection with p53-shRNA. These data are consistent with the existence of a specific cell-death pathway in neuronal cells in which S-nitrosylation of parkin inactivates its neuroprotective function at least in part by triggering p53-mediated apoptosis (Figure $4 D$ ).

\section{Pesticide-induced apoptosis in parkin-overexpressing SH-SY5Y neuroblastoma cells is mediated by $\mathrm{p} 53$}

Subsequently, we studied the mechanism of cell death induced by the herbicide paraquat $(\mathrm{PQ})$ and fungicide maneb (MB), the combination of which have been epidemiologically linked to human Parkinson's disease [27-29] and are known to induce selective loss of dopaminergic neurons in rodents [30-32]. Moreover, PQ and MB have been extensively used in both in vitro and in vivo models of Parkinson's disease [30-34].

In the present study, we transiently transfected $\mathrm{SH}$ SY5Y cells with the parkin-expression vector together with the GFP-p53-shRNA vector. As described previously, pcDNA and ctrl-shRNA vectors served as controls. We then incubated the cells with $100 \mu \mathrm{M}$ PQ and 


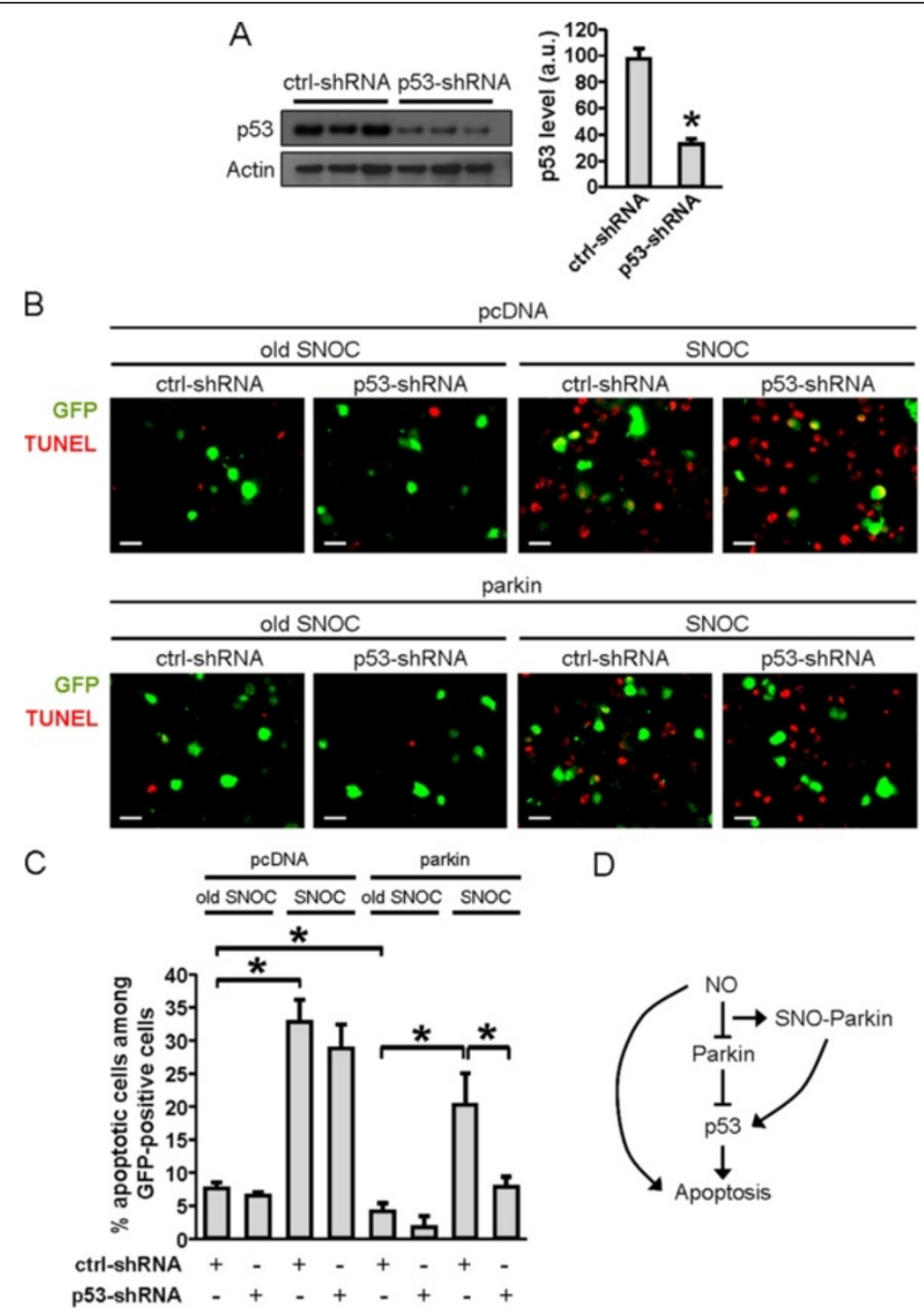

Figure 4 Role of p53 in NO-induced death in SH-SY5Y cells overexpressing parkin. $\boldsymbol{A}$, Validation of p53-shRNA as a gene-silencing tool. SHSY5Y cells were transfected with control (ctrl)- or p53 shRNA encoding plasmids, and the cell lysates subjected to western blotting using anti-p53 or actin antibodies. The optical density of the $\mathrm{p} 53$ bands was quantified and normalized to actin, $n=3 ;{ }^{*} p<0.01$. $\boldsymbol{B}$, Histological images of SHSY5Y cells transiently transfected with pcDNA or parkin plasmid. Cells were co-transfected with ctrl- or p53-shRNA plasmids that also encoded GFP (green). Cells were exposed to $600 \mu \mathrm{M}$ old or fresh SNOC $24 \mathrm{~h}$ prior to TUNEL (red) staining. Scale bar: $20 \mu \mathrm{m}$. $\boldsymbol{C}$, Percentage of TUNELpositive cells among GFP-positive cells under the designated conditions. Values are mean + SEM of 41-83 cells per condition performed in triplicate experiments; * $p<0.05$. $\boldsymbol{D}$, Schematic representation of the pathway linking NO to apoptosis in this system.

$10 \mu \mathrm{M}$ MB for 6 hours and identified apoptotic nuclei by TUNEL assay (Figure $5 A$ ). We then calculated the number of apoptotic cells as a percentage of total GFPpositive cells (Figure $5 B$ ).

The results obtained after exposure to $\mathrm{PQ} / \mathrm{MB}$ were similar to those obtained after exposure to SNOC. For example, p53-shRNA did not attenuate cell death in pcDNA-transfected cells after PQ/MB exposure. In contrast, in parkin-expressing cells, p53-shRNA abrogated PQ/MB-induced cell death, with the number of apoptotic cells returning to control values obtained in the absence of $\mathrm{PQ} / \mathrm{MB}$ exposure. In summary, both SNOC and $\mathrm{PQ} / \mathrm{MB}$ exposure triggered $\mathrm{p} 53$-dependent death in cells that were transfected with parkin.

\section{$\mathrm{PQ} / \mathrm{MB}$-induced neuronal cell death in primary} mesencephalic cultures is mediated by NO

We next studied the mechanism of $\mathrm{PQ} / \mathrm{MB}$-induced cell death in mesencephalic primary cultures, as dopaminergic neurons in this area of the brainstem are specific targets of these pesticides in PD. For this purpose, we prepared primary cultures of mesencephalon from 


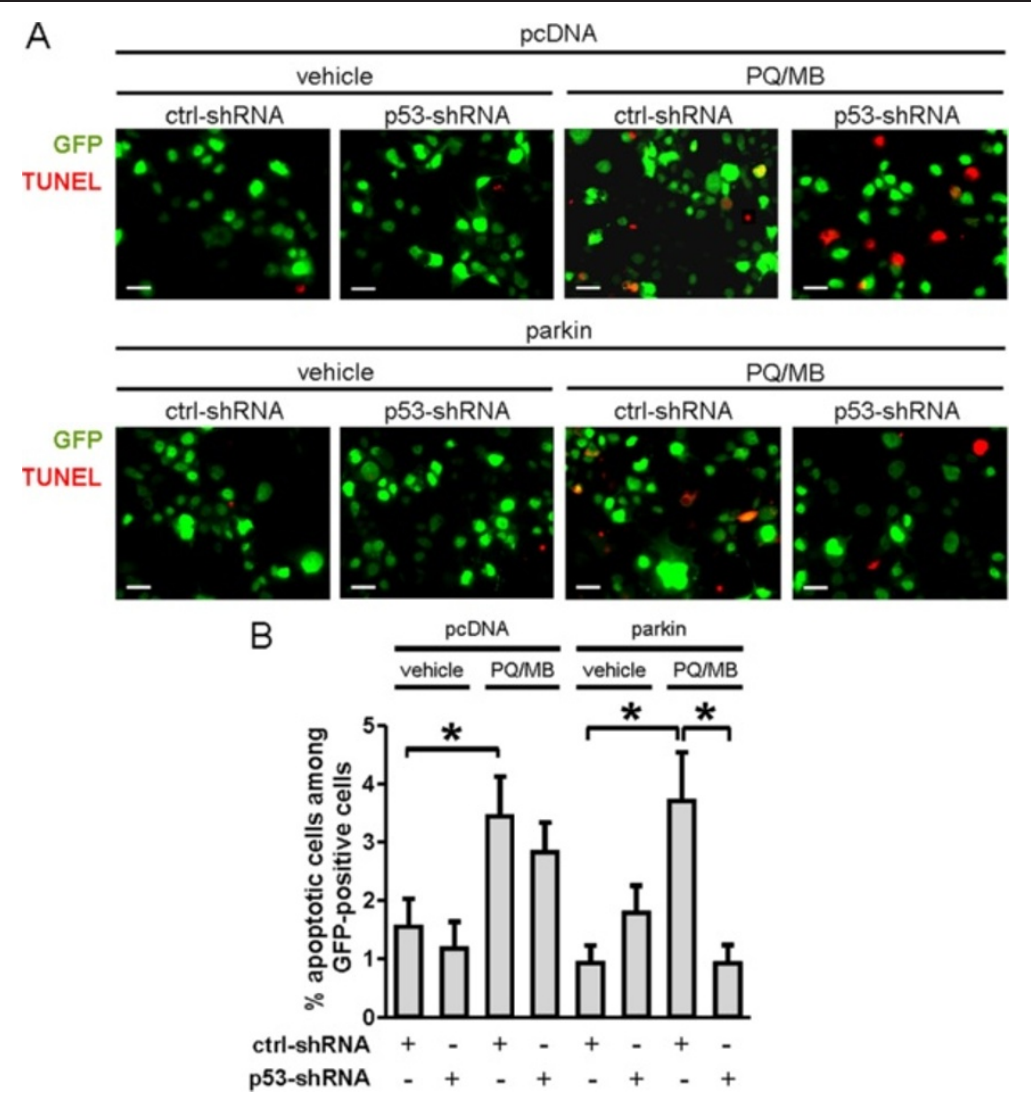

Figure 5 Role of p53 in herbicide/fungicide-induced apoptosis in SH-SY5Y cells overexpressing parkin. $\boldsymbol{A}$, Histological images of cells transiently co-transfected with plasmids for pcDNA or parkin, together with shRNA vectors coexpressing GFP (green). Cells were exposed to a combination of $100 \mu \mathrm{M}$ paraquat (PQ) and $10 \mu \mathrm{M}$ maneb (MB) or vehicle for $6 \mathrm{~h}$, fixed, and subjected to TUNEL staining (red). Scale bar: $20 \mu \mathrm{m}$. $\boldsymbol{B}$, Percentage of TUNEL-positive cells among GFP-positive cells under the indicated conditions. Values are mean + SEM of 183-656 cells per condition performed in triplicate experiments; ${ }^{*} p<0.05$.

embryonic day 13 rats. After 21 days in vitro (DIV), immunocytochemistry and immunoblot analyses revealed that mesencephalic cells positive for dopamine transporters (DAT) also expressed parkin (Figure 6A,B). We then exposed the cultured cells to $100 \mu \mathrm{M}$ PQ and 10 $\mu \mathrm{M} M B$ for 6 hours in the presence or absence of $1 \mathrm{mM}$ of the broad spectrum NO synthase (NOS) inhibitor $N^{G}$-nitro-l-arginine (NNA), and found significantly increased apoptotic death with $\mathrm{PQ} / \mathrm{MB}$ that was inhibited by NNA (Figure $6 C$ ). These results are consistent with the notion that $\mathrm{PQ} / \mathrm{MB}$-induced cell death in the mesencephalon is mediated predominantly by NO.

\section{SNO-parkin, p53 levels, and neuronal damage are increased in a mouse model of sporadic PD}

We next asked whether parkin is S-nitrosylated in vivo in animal models of PD induced by exposure to $P Q / M B$ in the presence or absence of the relatively neuronal specific NOS inhibitor 3-bromo-7-nitroindazole (3-Br-7$\mathrm{NI})$. Using the biotin-switch assay, we found a significant increase in S-nitrosylation of parkin (represented by the ratio of SNO-parkin/total parkin) in whole-brain lysates of $\mathrm{PQ} / \mathrm{MB}$-exposed mice compared to control brains (Figure 7). Moreover, SNO-parkin formation was attenuated by treatment with $3-\mathrm{Br}-7-\mathrm{NI}$, indicating that endogenous $\mathrm{NO}$ was responsible for this nitrosylation reaction. Concomitantly, p53 expression was increased in $\mathrm{PQ} / \mathrm{MB}$-exposed animals compared to controls, and 3-Br-7-NI significantly abrogated this increase in p53 (Figure 7).

To determine the pathological consequences of the $\mathrm{PQ} / \mathrm{MB}$-induced nitrosative stress, we performed immunohistological analyses on tissue samples prepared from these mice. Tyrosine hydroxylase $(\mathrm{TH})$ staining, representing dopaminergic neurons, was increased in the substantia nigra after 3-Br-7-NI treatment of PQ/ MB-injected mice (Figure 8). Similarly, immunohistochemistry for the general neuronal markers NeuN and MAP2 revealed that $\mathrm{PQ} / \mathrm{MB}$ injection caused neuronal loss in the basal ganglia and cerebral cortex, which was rescued by 3-Br-7-NI (Figure 8). Additionally, we quantified proliferating cell nuclear antigen (PCNA) staining in 


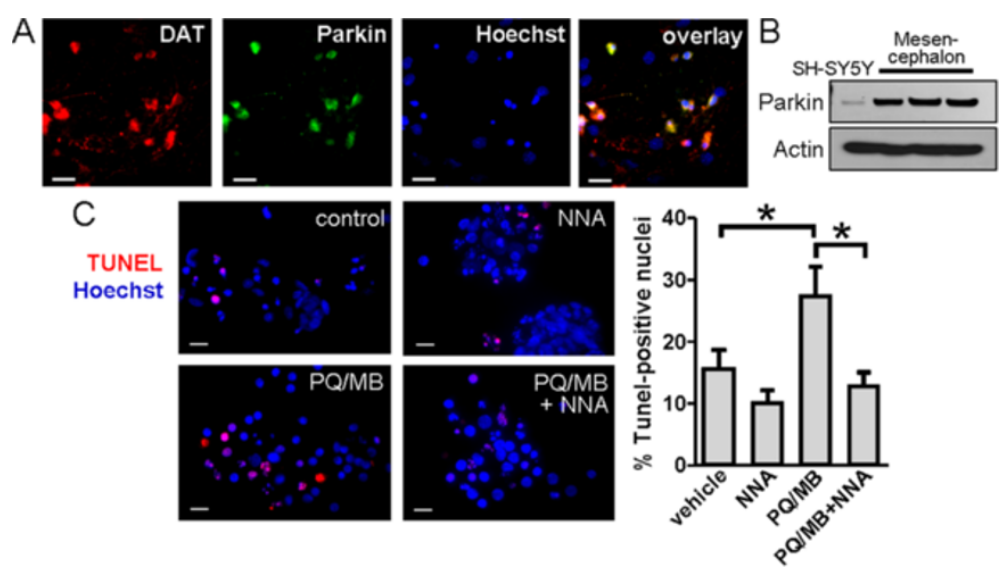

Figure 6 Role of NO in herbicide/fungicide-induced neuronal death in mesencephalic primary cultures. $\boldsymbol{A}$, Histological images of mesencephalic mixed cultures. Immunostaining for dopamine transporter (DAT, red), parkin (green), and Hoechst dye (blue). Scale bars: $20 \mu \mathrm{m}$. $\boldsymbol{B}$, Protein levels of parkin measured by western blot of cell lysates. $\boldsymbol{C}$, Images of primary cultures exposed to a combination of $100 \mu \mathrm{M}$ paraquat $(\mathrm{PQ})$ and $10 \mu \mathrm{M}$ maneb (MB), with $1 \mathrm{mM} \mathrm{N}_{\omega}$-nitro-L-arginine (NNA) or vehicle for $6 \mathrm{~h}$. Staining for TUNEL (red) and Hoechst (blue). Scale bar: 10 $\mu \mathrm{m}$. Quantification of the percentage of TUNEL-positive nuclei in each experimental condition shows PQ/MB induces cell death while NNA inhibits PQ/MB-induced death. Values are mean + SEM of 100-341 nuclei per condition performed in triplicate experiments; ${ }^{*} p<0.05$.

the dentate gyrus in order to assess progenitor cells responsible for adult neurogenesis in the hippocampus; we found that PCNA was significantly reduced after PQ/ MB injection, while 3-Br-7-NI treatment partially rescued this effect (Figure 8). Reduced proliferative capacity in human PD brain has been reported previously, and these agricultural chemicals can mimic this effect in mouse PD models [35-37]. To our knowledge, however, our new findings represent the first demonstration of partial rescue of adult neural stem cell proliferation by nNOS inhibition in a PD model caused by exposure to these pesticides. Furthermore, injection of $\mathrm{PQ} / \mathrm{MB}$ produced an increase in GFAP optical density in the cerebral cortex, hippocampus, and basal ganglia, consistent with previous observations that a reactive astrocytosis occurs in these rodents [30,32]; 3-Br-7-NI treatment largely inhibited this effect as well (Figure 8). Taken together, these results show that exposure to $\mathrm{PQ} / \mathrm{MB}$ in vivo leads to $\mathrm{S}$-nitrosylation of parkin, accompanied by increased p53 expression, astrocytosis, neuronal cell loss and decreased proliferation of neural stem cells, and that these adverse effects can be at least partially ameliorated by inhibition of nNOS.

\section{Correlation of increased SNO-parkin and p53 protein levels in human parkinsonian brains}

Given the aforementioned results, we predicted that human PD brain would exhibit increased levels of SNOparkin, which in turn would lead to increased p53 protein levels. To address this question, we obtained postmortem brains of patients with $\mathrm{PD}$ and incidental Lewy body disease (ILBD), along with unaffected control brains (Table 1). All brains had relatively short postmortem times and were flash frozen. We quantified the
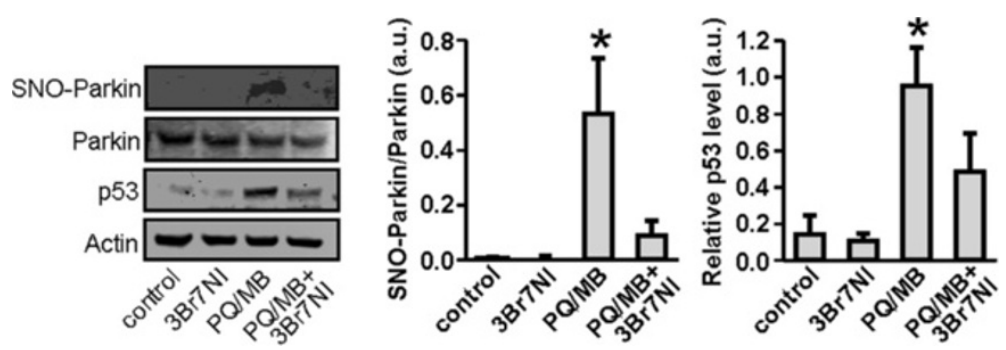

Figure 7 Increased S-nitrosylation of parkin and p53 levels in a mouse model of PD. Levels of S-nitrosylated parkin (SNO-parkin), total parkin, p53, and actin were examined by biotin-switch and western blot in mice treated with the nNOS inhibitor 3-Br-7-NI, PQ/MB, or PQ/MB with 3-Br-7-NI (left panel). Ratios of SNO-parkin and total parkin were quantified to indicate the extent of parkin S-nitrosylation under the indicated conditions (center panel). Quantifications of p53 signal were normalized to actin (right panel). Values are mean + SEM, $n=3$ mice per condition; $* p<0.05$. 


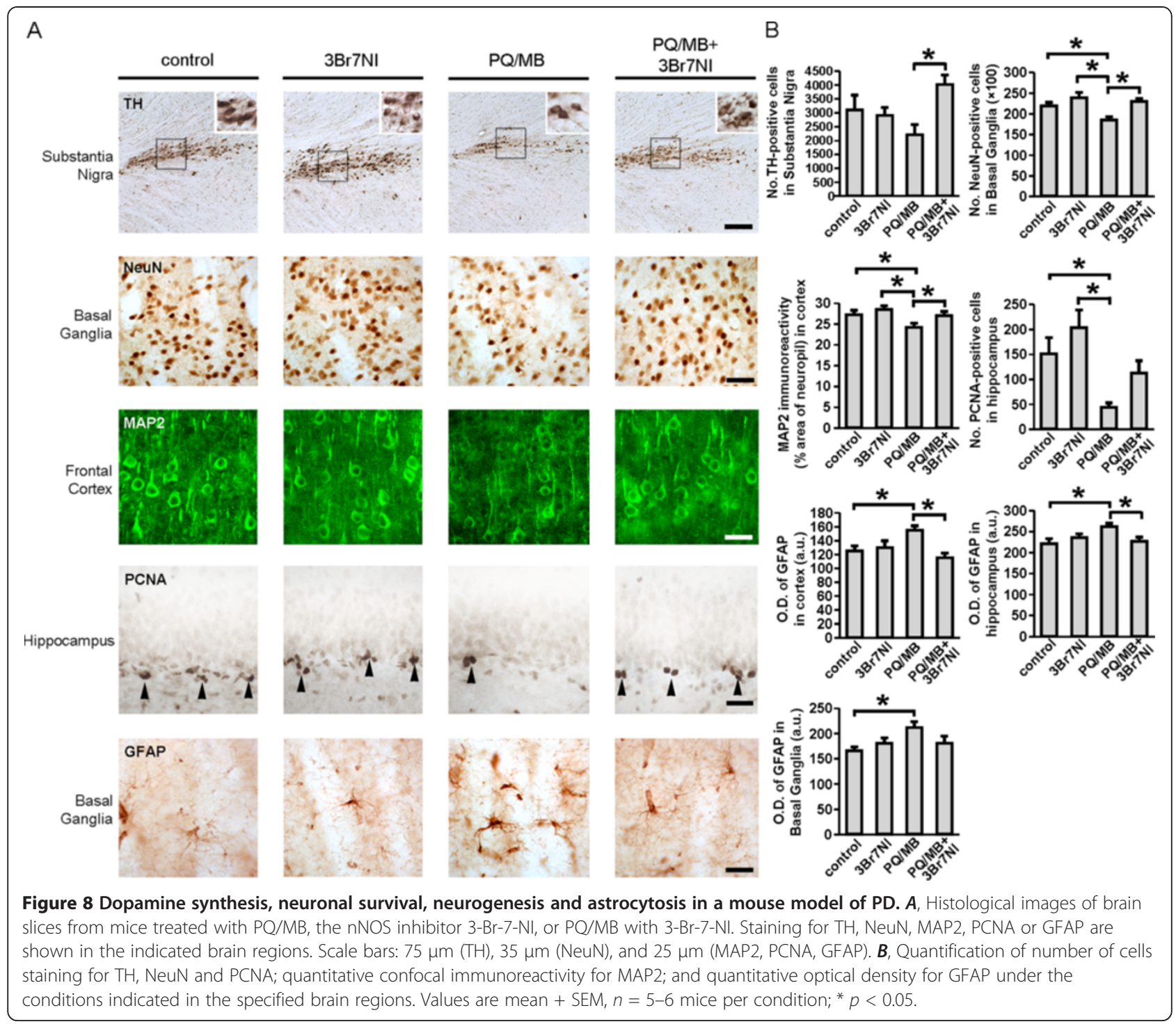

Table 1 Human brain samples

\begin{tabular}{ccccc}
\hline Conditions & $\begin{array}{c}\text { Lewy body } \\
\text { density score }\end{array}$ & Gender & Age (years) & PMI (hours) \\
\hline Ctrl & - & $\mathrm{m}$ & 81 & 2.75 \\
Ctrl & - & $\mathrm{m}$ & 82 & 3.66 \\
PD & 1 & $\mathrm{~m}$ & 69 & 4.16 \\
PD & 1 & $\mathrm{f}$ & 82 & 3 \\
PD & 1 & $\mathrm{~m}$ & 70 & 1.83 \\
PD & 1 & $\mathrm{f}$ & 73 & 2.16 \\
PD & 3 & $\mathrm{f}$ & 85 & 1.75 \\
ILBD & 1 & $\mathrm{~m}$ & 91 & 3.33 \\
ILBD & 3 & $\mathrm{~m}$ & 97 & 1.87
\end{tabular}

Posterior temporal cortical samples from unaffected control (ctrl), Parkinson's disease (PD) and Incidental Lewy body disease (ILBD) patients were analyzed. Each patient's clinical condition, Lewy body density score, gender $(m=$ male, $\mathrm{f}=\mathrm{female}$ ), age, and postmortem interval (PMI) are indicated. level of SNO-parkin in these brains by biotin-switch assay, and also total parkin and p53 protein levels by immunoblotting (Figure 9A). By quantitative densitometric analysis, we found the ratio of SNO-parkin to total parkin was increased in human PD brains by 15 -fold compared to control levels (2.33 a.u. vs 0.15 a.u; Figure $9 B$ ). In addition, we observed a consistent increase in p53 protein levels both in the brains of PD (1.39 a.u.) and ILBD (1.53 a.u.) compared to controls (0.08 a.u.), representing an increase of $>15$-fold in both disease states (Figure 9C). Finally, the ratio of SNO-parkin to total parkin was plotted against the p53 level for each sample (Figure 9D), and these two values were found to be highly correlated (Pearson correlation coefficient = 0.682). Taken together, both PD and ILBD human brains exhibited an increased SNO-parkin/parkin ratio, accompanied by an increase in p53 levels. 

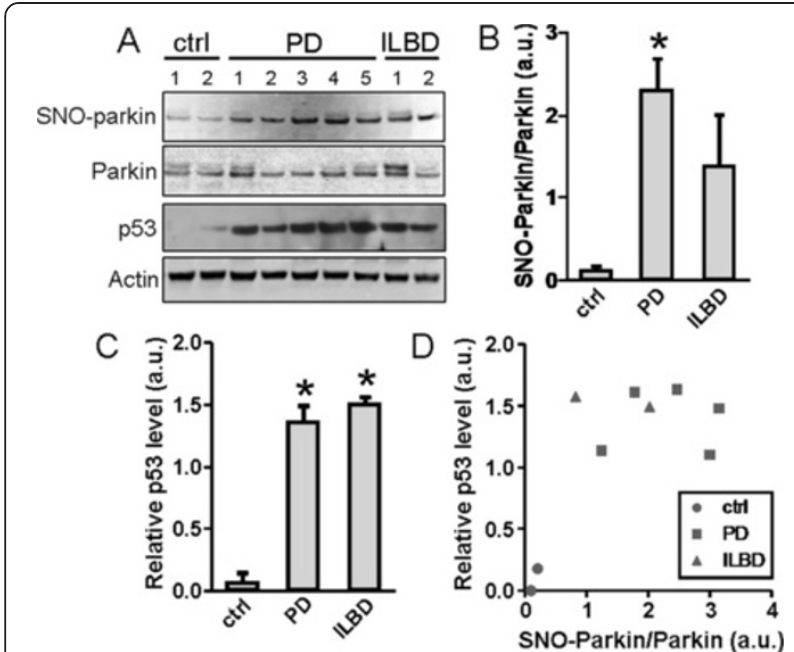

Figure 9 Increased S-nitrosylation of parkin and p53 levels in postmortem human brains from Parkinson's disease (PD) and Incidental Lewy body disease (ILBD). $\boldsymbol{A}$, Levels of SNO-parkin, total parkin, p53, and actin examined by biotin-switch and western blot in lysates prepared from unaffected control brains (ctrl) and brains with PD and ILBD. $\boldsymbol{B}$, Ratios of SNO-parkin relative to total parkin were calculated to indicate the extent of parkin S-nitrosylation in ctrl, PD and ILBD samples. Values are mean + SEM of samples from 2 control, 5 PD and 2 ILBD human brains; ${ }^{*} p<0.05$. C, p53 levels are quantified and normalized to actin for ctrl, PD and ILBD brains. Values are mean + SEM; ${ }^{*} p<0.01 . \boldsymbol{D}$, Ratios of SNO-parkin/parkin and p53/actin were plotted for each sample. The two values are positively correlated with a Pearson correlation coefficient of 0.682 and $p<0.05$.

\section{Discussion}

Previous reports had demonstrated a novel role of parkin as a transcriptional repressor of the tumor suppressor gene p53 [20]. In agreement with this observation, in the present study we found that parkin represses p53 promoter activity in cells expressing parkin either transiently or stably. In a recent article, Duplan and colleagues identified a parkin consensus binding sequence within the promoters of $\mathrm{p} 53$, presenilin 1 and presenilin 2. This GCCGGAG heptamer motif [38] is encompassed in the probes used in the EMSA experiments in the current study. Moreover, we found that the effect of parkin on p53 affects cell viability. Thus, the neuroprotective action of parkin is at least in part mediated by transcriptional suppression of $\mathrm{p} 53$, and this action appears to be independent of parkin's ubiquitin E3 ligase activity. Interestingly, recent studies also identified p53 as a transcriptional activator of parkin in human lung and colon cancer cell lines [39] as well as in gliomas [40]. However, in human neuronal cells, p53 does not appear to control parkin expression, and thus negative feedback regulation between parkin and p53 may not occur in neurons.

In the present work, we explore the role of a posttranslational modification, S-nitrosylation, on the neuroprotective effect of parkin that is mediated via p53 suppression. Even though exposure to NO donors can S-nitrosylate a number of other proteins, we have been able to elucidate the role of S-nitrosylated parkin by comparing results in cells with and without exogenously-expressed parkin. We report evidence that SNO-parkin attenuates the transcriptional repression of $\mathrm{p} 53$, and thus S-nitrosylation of parkin induces p53-mediated apoptosis in neuronal cells. Treatment with NO donors not only causes misslocalization of parkin but also inhibits the ability of parkin to bind to the p53 promoter sequence, as evidenced by EMSA and ChIP experiments. Therefore, it appears that the combination of these two effects may contribute to the cell death induced by parkin S-nitrosylation. Nonetheless, we do not rule out the possibility that the E3 ubiquitin ligase activity of parkin is also affected by nitrosative stress in PD, as indeed we and others have previously suggested $[24,26]$. Human sporadic PD has been epidemiologically linked to exposure to agricultural pesticides, particularly the simultaneous use of PQ and $\mathrm{MB}[4,5,27]$. Our data support the notion that pesticide-induced SNO modification of parkin may contribute to 'sporadic' forms of $\mathrm{PD}$, in a sense mimicking the effects of genetic mutations of parkin. In this regard, it should be noted that parkin-mediated control of p53 transcription is abrogated by several mutations of parkin that are known to cause familial PD [20]. In addition, Snitrosylation, as well as tyrosine phosphorylation, of parkin have been reported to abolish its ubiquitin ligase activity in sporadic forms of PD $[9,12,16,24,26,41]$. Taken together, these data provide a unifying view of a mechanism underlying the pathogenesis of some forms of both sporadic and familial PD; namely, posttranslational (or epigenetic) modifications of parkin can cause partial or total loss of parkin activity, mimicking the effects of genetic mutations.

Additionally, we found that inhibition of nNOS abated the neuronal apoptosis observed in a rodent model of PD induced by exposure to $\mathrm{PQ} / \mathrm{MB}$. We also demonstrate here for the first time that inhibition of nNOS can ameliorate $\mathrm{PQ} / \mathrm{MB}$-induced reduction in adult neural stem cell proliferation. These findings are consistent with a role for $\mathrm{NO}$ in these events. In corroboration of this conclusion, multiple other studies have suggested the involvement of NO in the apoptotic cell death of dopaminergic and other neurons that occurs in PD [42-45]. Importantly, human postmortem brain tissue from PD patients exhibit an upregulation of NOS, reactive nitrogen species [46-48], and reactive oxygen species $[10,49]$. Further, in several (but not all) reports, NO inhibits adult neurogenesis in the dentate gyrus [50,51], as observed here in PD mice produced by exposure to $\mathrm{PQ} / \mathrm{MB}$. We also found that nitrosative stress induced via pesticide exposure led to $S$-nitrosylation of parkin in these mice, contributing to dysfunctional parkin activity. Making these observations potentially relevant to the human condition, we and others have previously reported that SNO-parkin levels are dramatically elevated in human postmortem brains from sporadic PD patients [24,26]. 
Furthermore, in the present study we demonstrate in neural cells expressing parkin that NO-induced death is dependent on $\mathrm{p} 53$. While several studies have connected nitrosative stress with p53 accumulation [52-55], Snitrosylation of $\mathrm{p} 53$ does not seem to affect $\mathrm{p} 53$ binding to DNA [56]. In several experimental PD model systems, phosphorylation is known to activate p53 in neurons that subsequently undergo apoptosis [57-59]. Other reports have suggested a link between NO-induced processes, p53 activity and neuronal cell death, albeit the involvement of parkin was not yet known [60]. Moreover, in a number of PD model systems, inhibition of p53 has been shown to protect dopaminergic neurons and motor function $[61,62]$, as well as increase adult neural stem cell proliferation [63]. Taken together with prior reports, our findings support the notion that p53 is a downstream effector of parkin, in part responsible for the pathogenesis of PD. Importantly, we demonstrate that S-nitrosylation of parkin leads to pathological activation of the p53 gene, thus contributing to this pathogenic mechanism.

In support of this conclusion, we found in both a murine model of pesticide-induced 'sporadic' PD and in human cases of sporadic PD that the brain exhibits not only elevated SNO-parkin but also an increase in p53 protein levels, which is accompanied by neuronal cell loss. While prior reports had noted increased levels of p53 in human PD brain $[20,64,65]$, in the present study, we also found a striking positive correlation between parkin S-nitrosylation and p53 protein levels, thus supporting a possible link between these two events.

In summary, parkin is a neuroprotective molecule that binds to the promoter region of the p53 gene, thus suppressing its activity under physiological conditions. In the present work we propose that in the presence of pesticides or other forms of environmental stress leading to the excessive generation of $\mathrm{NO}$, parkin becomes $\mathrm{S}$ nitrosylated. SNO-parkin, in turn, is excluded from the nucleus and loses its ability to bind to the p53 promoter sequence (Figure 10). This leads to relative activation of the p53 gene and increased levels of p53 protein, hence contributing to apoptotic cell death in affected neurons.

\section{Conclusions}

In the present study, we show that S-nitrosylation of parkin leads to transcriptional activation of the p53 gene. This reaction may underlie, at least in part, the pathogenesis of sporadic PD. The discovery of this pathway affords an opportunity for developing novel therapeutics for PD.

\section{Methods}

\section{Cell cultures, transfections and treatments}

HEK-293 and SH-SY5Y cells were maintained in Dulbecco's modified Eagle's medium (DMEM, Sigma) supplemented with $10 \%$ of heat-inactivated fetal bovine serum (FBS,
HyClone), 2 mM L-glutamine (Gibco-Invitrogen), 50 $\mathrm{IU} / \mathrm{ml}$ penicillin (Omega Scientific) and $50 \mathrm{\mu g} / \mathrm{ml}$ streptomycin (Omega Scientific). Cells were cultured in $100 \mathrm{~mm}$ culture plates at $37^{\circ} \mathrm{C}$ in a water-saturated atmosphere of $95 \%$ air and $5 \% \mathrm{CO}_{2}$. The SH-SY5Y cell line stably overexpressing parkin (Parkin-SY5Y cells) was prepared by selecting the transfectants with geneticin (Gibco-Invitrogen). Parkin-SY5Y cells were maintained in DMEM supplemented with 10\% FBS, 2 $\mathrm{mM}$ l-glutamine, $50 \mathrm{IU} / \mathrm{ml}$ penicillin, $50 \mu \mathrm{g} / \mathrm{ml}$ streptomycin and $100 \mu \mathrm{g} / \mathrm{ml}$ geneticin. Transfections were performed in 6-well plates using Lipofectamine LTX and Plus Reagent (Invitrogen) according to the manufacturer's instructions.

Cultures of neuroblastoma cell lines were grown in 6well plates. When indicated, cells were exposed for 6-24 hours with 200-600 $\mu \mathrm{M}$ of the short-half life nitric oxide donor S-nitrosocysteine (SNOC), or control solution from which NO had been previously dissipated (designated 'old' SNOC). Additional exposures included $200 \mu \mathrm{M}$ of the long-half life NO donor S-nitrosoglutathione (GSNO) or glutathione $(\mathrm{GSH})$ as its negative control. The neuroblastoma cell line and mesencephalic primary cultures containing substantia nigra cells were exposed to pesticides previously linked to PD in epidemiological studies, including $100 \mu \mathrm{M}$ of the herbicide paraquat (PQ; Fluka) and $10 \mu \mathrm{M}$ of the fungicide maneb (MB; Fluka). These concentrations were chosen as approximately two-fold the maximal allowed exposure level from EPA data (US EPA codes CASRN 1910-42-5 and CASRN 12427-38-2, respectively). In some cases, $1 \mathrm{mM}$ of the broad spectrum NOS inhibitor $\mathrm{N}^{\mathrm{G}}$-nitro-L-Arginine (NNA; Alexis) was added. Cells were exposed for 6 hours at $37^{\circ} \mathrm{C}$ in a watersaturated atmosphere of $95 \%$ air and $5 \% \mathrm{CO}_{2}$. Recombinant proteins were exposed to $200 \mu \mathrm{M}$ SNOC or old SNOC for $10 \mathrm{~min}$ at room temperature.

\section{Primary mesencephalic cultures}

Mixed mesencephalic primary cultures, including substantia nigra, were prepared from embryonic day-13 (E13) fetuses of Sprague-Dawley rats. The mesencephalon was dissected in ice-cold EBSS (Gibco-Invitrogen) and subsequently digested in $0.25 \%$ trypsin (Gibco-Invitrogen) for 35 minutes at $37^{\circ} \mathrm{C}$ in a $7 \% \mathrm{CO}_{2}$ humidified incubator. Tissues were washed with pre-incubation medium containing DMEM Ham's F-12 (1:1) (Omega Scientific), $10 \%$ fetal bovine serum (FBS, HyClone), $50 \mathrm{IU} / \mathrm{ml}$ penicillin (Omega Scientific) and $50 \mu \mathrm{g} / \mathrm{ml}$ streptomycin (Omega Scientific) and dissociated by trituration. Cells were plated on 24-well plates coated with poly-1-lysine (Sigma) in 1:1 pre-incubation medium combined with incubation medium, the latter containing DMEM Ham's F-12, $0.5 \mathrm{mM}$ l-glutamine (Gibco-Invitrogen), 1\% B27 (Gibco-Invitrogen), $50 \mathrm{IU} / \mathrm{ml}$ penicillin and $50 \mu \mathrm{g} / \mathrm{ml}$ 


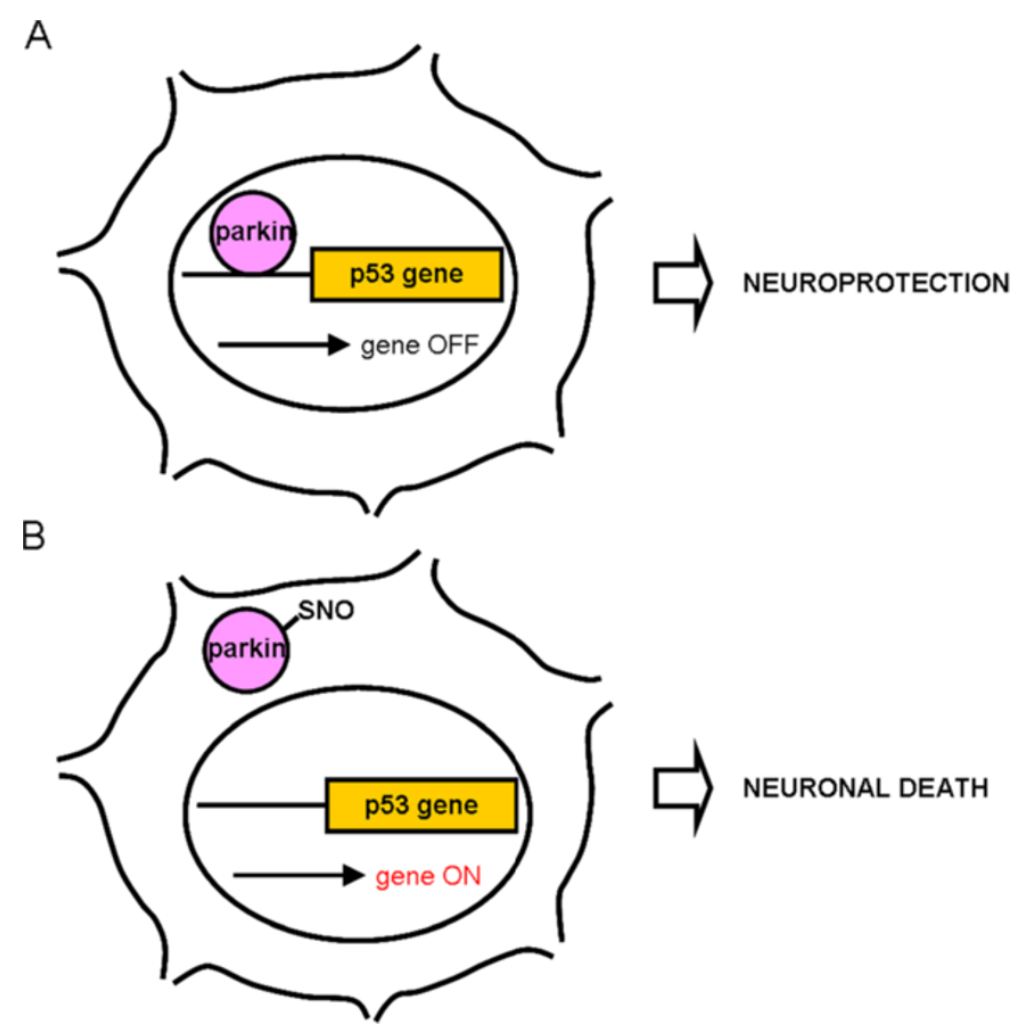

Figure 10 Schematic representation of proposed mechanism whereby S-nitrosylation of parkin regulates p53-mediated neuronal death in sporadic PD. A, Under physiological conditions, parkin is neuroprotective by repressing p53 transcription. $\boldsymbol{B}$, During nitrosative stress, for example due to pesticide exposure, parkin becomes S-nitrosylated. SNO-parkin no longer binds to the p53 promoter and is excluded from the nucleus. This results in activation of the p53 gene and subsequent p53-mediated neuronal death.

streptomycin, and maintained at $37^{\circ} \mathrm{C}$ in a $5 \% \mathrm{CO}_{2}$ humidified incubator; 24 hours after plating, the entire medium was replaced with incubation medium. Subsequently, half of the incubation medium was replaced once every four days. At 21 days in vitro (DIV), cells were fixed with $4 \%$ paraformaldehyde or treated according to the specific experimental design. The percentage of dopaminergic neurons in the mixed mesencephalic primary culture was $35 \pm 4.5 \%$, as measured by immunocytochemistry for the dopamine transporter.

\section{Human brain tissue}

Human brain tissues were provided by the Banner Sun Health Research Institute Brain and Body Donation Program. All sample groups correspond to the posterior temporal cortex, from the middle temporal gyrus at the coronal level of the end of the lateral fissure. Samples were frozen $\left(-80^{\circ} \mathrm{C}\right)$ within less than 5 hours postmortem (Table 1) and homogenized with HENTS buffer, $\mathrm{pH}$ 7.2 (100 mM Hepes, $1 \mathrm{mM}$ EDTA, $0.1 \mathrm{mM}$ neocuproine, $1 \%$ Triton X-100, $0.1 \%$ sodium dodecyl sulfate) prior to biochemical analysis. The "control" group included samples from elderly patients with no history of dementia or other neurological diseases (Table 1). The "Parkinson's disease" (PD) group included samples from 5 different brains obtained from patients whose clinical diagnosis in life was verified at postmortem examination (males and females, $69-85$ years old; Table 1). The "incidental Lewy body disease" (ILBD) group included samples from 2 clinically normal individuals but whose autopsy revealed the presence of Lewy bodies in the central nervous system by means of $\alpha$-synuclein immunohistochemistry (males, 91-97 years old; Table 1).

\section{Mouse model of sporadic PD from pesticide exposure}

Animal care was conducted in accordance with the United States Public Health Service Guide for the Care and Use of the Laboratory Animals, and all experiments were approved by the University of California San Diego Institutional Animal Care and Use Committee. Exposure to the combination of pesticides paraquat (PQ) and maneb (MB) has been linked to sporadic cases of human PD in epidemiological studies [27-29] and can produce selective loss of nigrostriatal dopaminergic cell bodies and reduction in dopamine levels in the rodent striatum; the combination of paraquat and maneb has therefore 
been used as an experimental model of PD induced by pesticides in rodents $[30-33,66]$. Female mice weighing 20-30 g were injected intraperitoneally (i.p.) with freshly prepared paraquat (Fluka; $5 \mathrm{mg} / \mathrm{kg}$ ) and maneb (Fluka; $15 \mathrm{mg} / \mathrm{kg}$ ) twice a week for four weeks. Additional groups of animals also received the relatively specific neuronal NOS inhibitor 3-bromo-7-nitroindazole (3-Br$7-\mathrm{NI}$, Enzo Life Sciences; $30 \mathrm{mg} / \mathrm{kg})$ or vehicle $(60 \%$ DMSO in PBS) twice a week on alternate days for four weeks. Animals were sacrificed after treatment. Half of each brain was frozen at $-80^{\circ} \mathrm{C}$ ) and homogenized in HENTS buffer prior to biochemical analysis. The remaining halves were fixed in $4 \%$ paraformaldehyde for histological assessment of neuronal damage.

\section{Postmortem processing and immunohistochemistry}

To evaluate the neurodegenerative histological alterations after pesticide exposure, blind-coded $40-\mu \mathrm{m}$ thick vibratome sections from mouse brains fixed in $4 \%$ paraformaldehyde were immunolabeled for different markers. To assess the integrity of the dendritic system, sections were immunolabeled with the mouse monoclonal antibody against the dendritic marker microtubule-associated protein 2 (MAP2; 1:40; Chemicon, Temecula, CA), as previously described [67]. To evaluate neuronal damage, blind-coded sections were immunolabeled with mouse monoclonal antibody against the neuronal marker NeuN (1:500; Millipore, Billerica, MA). To assess astroglial response, tissue was incubated with the astroglial marker glial fibrillary acidic protein (GFAP; 1:500; Dako, Fort Collins, CO), as previously described $[62,67]$. For the evaluation of dopamine synthesis, sections were incubated with mouse anti-TH antibody (1:1000; Pel-Freez). To assess proliferation capacity of adult stem cells that are critical for neurogenesis, tissue was pre-treated with formamide and $\mathrm{HCl}$ to denature DNA. Blind-coded sections were then immunolabeled with mouse monoclonal antibody against PCNA (1:500; Santa Cruz Biotechnology, Santa Cruz, CA).

After overnight incubation with the specific primary antibody, for the detection of MAP2, sections were incubated with FITC-conjugated horse anti-mouse IgG secondary antibody (1:75, Vector Laboratories, Burlingame, CA), transferred to SuperFrost slides (Fisher Scientific, Tustin, $\mathrm{CA}$ ) and mounted under glass coverslips with anti-fading media (Vector). The immunolabeled blind-coded sections were imaged with the laser scanning confocal microscope (MRC1024, Bio-Rad, Hercules, CA) and analyzed with the Image 1.43 program $(\mathrm{NIH})$, as previously described [33,59]. For the detection of TH, NeuN, PCNA and GFAP, sections were incubated with biotinylated secondary antibody and avidin-conjugated peroxidase (both Vector). Staining was visualized by incubating in diaminobenzidine solution according to the manufacture's directions (all from Vector
Laboratories, Burlingame, CA) and analyzed with the Quantimet 570C densitometer [33].

All sections were processed under the same standardized conditions. For each mouse, a total of 3 sections were analyzed and for each section, 4 fields in the specific brain region were examined. Results for all images were averaged and expressed as the percentage area covered by immunoreactive dendrites in the case of MAP2, as number of positive neurons per square millimeter in the case of TH, NeuN and PCNA, and as corrected optical density in the case of GFAP.

\section{Luciferase reporter gene activity assay}

Cells were seeded in 6-well plates, allowed to adhere overnight, and then co-transfected in each well with 1.5 $\mu \mathrm{g}$ of p53-responsive luciferase reporter plasmid DNA (kindly donated by Dr. Stephen H. Safe, Department of Veterinary Physiology and Pharmacology at Texas A\&M University) and $0.5 \mu \mathrm{g}$ of Renilla luciferase cDNA; in some experiments1 $\mu \mathrm{g}$ of wild-type human parkin cDNA construct was also transfected. The total amount of plasmid DNA per transfection was kept constant (3 $\mu \mathrm{g}$ per well) by balancing the total transfected DNA amount with empty vector pcDNA3 (Invitrogen). After incubation for 48 hours, cells were exposed to various protocols, according to the specific experimental design. Approximately 72 hours after transfection, cells were lysed in $1 \mathrm{x}$ reporter lysis buffer (Promega), $20 \mu \mathrm{l}$ of cell extract was placed in each well of a 96-well plate, and firefly and Renilla luciferase activity were measured in a luminometer with a dual-luciferase reporter assay system following the manufacturer's instructions (Promega). Firefly luminescence was normalized to the Renilla luminescence signal.

\section{Protein extraction and western blot analyses}

Cultured cells were harvested and lysed in RIPA buffer (50 mM Tris- $\mathrm{HCl} \mathrm{pH}$ 8.0, $150 \mathrm{mM} \mathrm{NaCl}, 1 \%$ Nonidet P-40, $0.5 \%$ deoxycholate, $0.1 \%$ sodium dodecyl sulphate) for $10 \mathrm{~min}$ at $4^{\circ} \mathrm{C}$. Protein concentrations were determined using the Bio-Rad protein assay dye according to the manufacturer's specifications. For immunoblotting, typically 5-30 $\mathrm{\mu g}$ of proteins were resolved on $4-12 \%$ polyacrylamide NuPAGE-MES gels (Invitrogen) and then wet-transferred to PVDF membranes (Millipore). Membranes were blocked in $2 \%$ skim milk in Tris-buffered saline (TBS) containing 1\% Tween-20 (TBS-T). Immunoblotting was performed using mouse anti-parkin monoclonal antibody (1:1,000; MAB5512, Millipore), rabbit anti-p53 polyclonal antibody (1:1,000; 9282, Cell Signaling), mouse anti-p53 monoclonal antibody (1:1,000; SC-99, Santa Cruz), mouse monoclonal anti- $\beta$-actin antibody (1:5,000; MAB1501, Millipore), or rabbit polyclonal anti- $\beta$-actin antibody 
(1:5,000; 4967, Cell Signaling) for mouse samples. For cell line experiments, immunological complexes were detected with goat anti-mouse (1:3,000; Jackson) or goat anti-rabbit (1:3,000; BioRad) IgG secondary antibodies coupled to peroxidase, followed by electrochemiluminescence using the Super Signal substrate kit (Thermo Scientific) as directed by the manufacturer. For human and mouse brain lysates, goat anti-mouse at 680 LT (1:20,000; Li-Cor) or goat anti-rabbit at 800 CW (1:15,000; Li-Cor) IR-dye-conjugated secondary antibodies were used, followed by infrared analysis with Odyssey (Li-Cor). When p53 was analysed in the human neuroblastoma cell line, polyclonal antibody antip53 was used. In human and mouse brain samples, p53 was detected using the monoclonal antibody SC-99 (Santa Cruz).

Densitometric analysis of protein bands was performed using Adobe Photoshop. All values were normalized to their respective loading controls.

\section{Biotin-switch assay for detection of S-nitrosylated proteins}

Analysis of S-nitrosylated parkin (SNO-parkin) with the biotin-switch assay was performed as previously described [26,68,69]. Briefly, fresh brain tissue samples were homogenized in HEN buffer, pH 7.2 (100 mM Hepes, $1 \mathrm{mM}$ EDTA, $0.1 \mathrm{mM}$ neocuproine) with 1\% Triton $\mathrm{X}-100$ and $0.1 \%$ sodium dodecyl sulfate. A total of 1 mg of protein per sample was used for the assay. Free thiol groups were blocked by incubation with $20 \mathrm{mM}$ methyl methanethiol-sulfonate (MMTS; Aldrich) for 30 $\min$ at $50^{\circ} \mathrm{C}$. Cell extracts were then precipitated with acetone and resuspended in HEN buffer with 1\% SDS. $\mathrm{S}$-Nitrosothiol groups were then selectively reduced by $75 \mathrm{mM}$ ascorbate to free thiols, which were subsequently biotinylated with $4 \mathrm{mM}$ N-[6-(biotinamido)hexyl]-3'(2' -pyridyldithio)-propionamide (biotin-HPDP; Soltec Ventures). The biotinylated proteins were pulled down with streptavidin-agarose beads and analyzed by immunoblotting. Total protein as a loading control was quantified by standard immunoblot analysis. Results were expressed as SNO-parkin relative to total parkin for each sample.

\section{Immunocytochemistry and nuclear staining}

Cell cultures were fixed in $4 \%$ paraformaldehyde in PBS for $10 \mathrm{~min}$, and then permeabilized with $0.1 \%$ Triton $\mathrm{X}$ 100 and blocked with $5 \%$ goat serum for $30 \mathrm{~min}$. Mouse anti-myc (46-0603, Invitrogen), mouse anti-parkin (MA B5512, Millipore) or rat anti-dopamine transporter (AB5990, Abcam) monoclonal antibodies were used at 1:500 dilution $\left(4^{\circ} \mathrm{C}\right.$ overnight incubation). Goat antimouse FITC- (115-095-166, Jackson ImmunoResearch) or goat anti-rat rhodamine red-conjugated (112-295-075,
Jackson ImmunoResearch) secondary antibodies were used for fluorescence labeling at a dilution of 1:500 (RT, 1 hour). Nuclei were detected by co-staining with $12 \mu \mathrm{M}$ Hoechst 33342 (Molecular Probes) for $30 \mathrm{~min}$. Coverslips were mounted for immunofluorescence analysis using Fluoro Gel mounting medium (Electron Microscopy Sciences), and analysis of samples was performed on a deconvolution epifluorescence microscope (Axio, Carl Zeiss Microimaging $\mathrm{GmbH}$ ).

\section{Terminal-deoxynucleotidyl-transferase dUTP nick end labeling (TUNEL) assay}

For neuroblastoma cultures, cells were collected and TUNEL assay was performed in suspension. For primary neuronal cultures, TUNEL assay was performed on coverslips. Briefly, cells were fixed with $4 \%$ paraformaldehyde in PBS for $10 \mathrm{~min}$, and then permeabilized with $0.1 \%$ Triton X-100 and $0.1 \%$ sodium citrate for $2 \mathrm{~min}$. Apoptotic cells were labeled using an in situ cell death detection kit (Roche) according to the manufacturer's instructions. Coverslips were mounted using Fluoro Gel mounting medium, and apoptotic cells were observed and quantified on a deconvolution epifluorescence microscope.

\section{RNAi-mediated knockdown of p53}

psiRNA vector expressing short hairpin RNA for efficiently targeting and silencing human p53 gene (shRNAp53) was purchased from InvivoGen (psirna42-hp53). Briefly, shRNA-p53 was produced with the psiRNAh7SKGFPzeo plasmid from the human 7SK RNA pol III promoter, featuring a GFP-Zeo fusion gene for monitoring transfection efficiency. psiRNA plasmid targeting luciferase-GL3, whose sequence was not found in the mouse, human or rat genome databases [70,71], was used as a non-targeting control (shRNA-ctrl; InvivoGen). shRNA vectors were amplified in competent $E$. coli GT116 cells according to the manufacturer's instructions. Transfection of neuroblastoma cells with shRNAs was performed in 6-well plates using Lipofectamine LTX and Plus Reagent (Invitrogen). A total of $3 \mu \mathrm{g}$ of plasmid DNA per well was used for each transfection.

\section{Recombinant protein expression and purification}

Recombinant GST-tagged parkin protein was expressed and purified as previously described [26].

\section{Chromatin immunoprecipitation (ChIP) assay}

ChIP assays were performed using the ChIP-IT EXPRESS assay kit protocol (Active Motif, USA). Briefly, $1 \times 10^{7}$ SH-SY5Y cells that had been transfected with pcDNA or parkin were exposed to $200 \mu \mathrm{M}$ GSNO or GSH (as a control) for 4 hours. Cells were then cross-linked with $1 \%$ formaldehyde at room temperature for $10 \mathrm{~min}$, washed with 
PBS and lysed, followed by centrifugation at $2400 \times g$. The nuclear pellet was resuspended in shearing buffer and sonicated with 8 pulses of $20 \mathrm{~s}$ each to shear DNA into 200-1000 bp fragments. Ten percent of the mixture containing protein/DNA complexes was used for "input DNA" analysis. An equal amount of the protein/DNA complex mixture was then incubated at $4^{\circ} \mathrm{C}$ overnight with magnetic beads and control IgG or an anti-parkin antibody (MAB5512, Chemicon International, USA). Immunoprecipitated DNA was then eluted from the magnetic beads and the cross-linking was reversed. Input and ChIP DNA were analyzed using quantitative real-time PCR. The human $\mathrm{p} 53$ promoter region was amplified using forward primer $5^{\prime}$-CTCCAAAATGA TTTCCACCAA-3' and reverse primer 5'-GGAAGCA AAGGAAATGGAGTT-3' for determination of parkin binding. For quantitative ChIP, the PCR was performed using EXPRESS SYBR GreenER ${ }^{\mathrm{TM}}$ (Invitrogen, USA) on the Stratagene Mx3000P Q-PCR system. Levels of enrichment ( $\mathrm{n}$-fold) were calculated using the comparative cycle threshold method.

\section{Electrophoretic mobility shift assay (EMSA)}

A synthetic oligonucleotide covering the region of the human p53 promoter (Pp53 forward and reverse; see below) [20] labeled with biotin at the $5^{\prime}$ end was obtained from IDT Integrated DNA Technologies and subsequently annealed. For detection of binding of parkin to p53, $1 \mu \mathrm{M}$ recombinant, wild-type parkin was incubated with $0.1 \mathrm{nM}$ biotin-labeled DNA oligonucleotide. The specificity of the reaction was verified by incubation of Pp53 with increasing concentrations of recombinant parkin, typically from 100 $\mathrm{nM}$ to $1 \mu \mathrm{M}$. Binding reactions were performed at room temperature for $20 \mathrm{~min}$ in $1 \mathrm{x}$ binding buffer (Panomics). Then, protein-DNA complexes were resolved by electrophoresis on $6 \%$ polyacrylamide Novex DNA retardation gels (Invitrogen) at $100 \mathrm{~V}$ in $0.5 \mathrm{x}$ TBE buffer, pH 8.3 (90 mM Tris- $\mathrm{HCl}, 90 \mathrm{mM}$ boric acid, 2 $\mathrm{mM}$ EDTA), and wet-transferred to biodyne $\mathrm{B}$ nylon membranes (Pall Life Sciences). Oligonucleotides were fixed to the membrane by UV crosslinking at $254 \mathrm{~nm}$ for $5 \mathrm{~min}$. After blocking the membrane with $1 \mathrm{x}$ blocking buffer (Thermo Scientific), biotinylated oligonucleotides were detected by incubation with stabilized streptavidin-horseradish peroxidise conjugate (Thermo Scientific), followed by electrochemiluminescence analysis using a substrate kit (Thermo Scientific) as directed by the manufacturer.

Pp53 forward: 5'-GGCACCAGGTCGGCGAGAATC CTGACTCTGCACCCTCCTCCC CAACTCCATTTCC TTTGCTTCCTCCGGC-3'.

Pp53 reverse: 5'-GCCGGAGGAAGCAAAGGAAATG GAGTTGGGGAGGAGGGTGC AGAGTCAGGATTCT CGCCGACCTGGTGCC-3'.

\section{Statistical analysis}

Data were quantified and stored in Excel software format (Microsoft, Redmond, WA). Graphs depicting data from quantitative analyses were generated with PRISM software (GraphPad Software). All experimental points are expressed as mean \pm SEM. Statistical differences among different groups were determined by Student's t-test (for single comparisons) or ANOVA (for multiple comparisons) using PRISM software.

\section{Abbreviations}

GSH: Glutathione; GSNO: S-nitrosoglutathione; ILBD: Incidental Lewy body disease; MB: Maneb; NNA: N ${ }^{G}$-nitro-L-Arginine; NO: Nitric oxide; NOS: Nitric oxide synthase; PD: Parkinson's disease; PQ: Paraquat; SNO: S-nitrosothiol; SNOC: S-nitrosocysteine.

\section{Competing interests}

The authors declare that they have no competing interests.

\section{Authors' contributions}

CRS, TN, NN and SAL designed the study. CRS, TN, ER, MM, AA, SFC and TF-N performed relevant research and/or acquisition of data. CRS, TN, SFC, EM, NN and SAL contributed to the analysis and interpretation of data. CRS, TN, EM, NN and SAL drafted the manuscript and revised it critically. All authors read and approved the final manuscript.

\section{Acknowledgments}

This work was supported in part by a postdoctoral fellowship of the Spanish Ministry of Education and Science (Programa Nacional de Movilidad de Recursos Humanos del Plan Nacional de I+D+i 2008-2011), by NIH grants P01 HD29587, P01 ES01673, and P30 NS076411, and by grants from the Michael J Fox Foundation. We are grateful to the Banner Sun Health Research Institute Brain and Body Donation Program of Sun City, Arizona, for providing the human brain tissues. We thank Dr. Stephen H. Safe (Department of Veterinary Physiology and Pharmacology at Texas A\&M University) for kindly providing the p53 construct for reporter assay. We thank Dr. Xiaoqing Li for her assistance on EMSA experiments. We thank Dr. Mohd Waseem Akhtar for his scientific advice.

Received: 1 June 2013 Accepted: 16 August 2013

Published: 28 August 2013

\section{References}

1. Mayeux R, Marder K, Cote LJ, Denaro J, Hemenegildo N, Mejia H, Tang MX, Lantigua R, Wilder D, Gurland B, et al: The frequency of idiopathic Parkinson's disease by age, ethnic group, and sex in northern Manhattan, 1988-1993. Am J Epidemiol 1995, 142:820-827.

2. Giasson $\mathrm{Bl}$, Lee VM: Are ubiquitination pathways central to Parkinson's disease? Cell 2003, 114:1-8.

3. Jenner P: Oxidative stress in Parkinson's disease. Ann Neurol 2003, 3(53):S26-36. discussion S36-28.

4. Betarbet R, Sherer TB, MacKenzie G, Garcia-Osuna M, Panov AV, Greenamyre $\mathrm{JT}$ : Chronic systemic pesticide exposure reproduces features of Parkinson's disease. Nat Neurosci 2000, 3:1301-1306.

5. Langston JW: Parkinson's disease: current and future challenges. Neurotoxicology 2002, 23:443-450.

6. Kitada T, Asakawa S, Hattori N, Matsumine H, Yamamura Y, Minoshima S, Yokochi M, Mizuno Y, Shimizu N: Mutations in the parkin gene cause autosomal recessive juvenile parkinsonism. Nature 1998, 392:605-608.

7. Lucking CB, Durr A, Bonifati V, Vaughan J, De Michele G, Gasser T, Harhangi BS, Meco G, Denefle P, Wood NW, et al: Association between early-onset Parkinson's disease and mutations in the parkin gene. The New England journal of medicine 2000, 342:1560-1567.

8. Oliveira SA, Scott WK, Martin ER, Nance MA, Watts RL, Hubble JP, Koller WC, Pahwa R, Stern MB, Hiner BC, et al: Parkin mutations and susceptibility alleles in late-onset Parkinson's disease. Ann Neurol 2003, 53:624-629.

9. Shimura H, Hattori N, Kubo S, Mizuno Y, Asakawa S, Minoshima S, Shimizu N, Iwai K, Chiba T, Tanaka K, Suzuki T: Familial Parkinson disease gene product, parkin, is a ubiquitin-protein ligase. Nat Genet 2000, 25:302-305. 
10. Zhang Y, Gao J, Chung KK, Huang H, Dawson VL, Dawson TM: Parkin functions as an E2-dependent ubiquitin- protein ligase and promotes the degradation of the synaptic vesicle-associated protein, CDCrel-1. Proc Natl Acad Sci U S A 2000, 97:13354-13359.

11. Bence NF, Sampat RM, Kopito RR: Impairment of the ubiquitinproteasome system by protein aggregation. Science 2001, 292:1552-1555.

12. Dawson TM, Dawson VL: Molecular pathways of neurodegeneration in Parkinson's disease. Science 2003, 302:819-822.

13. Feany $M B$, Pallanck $\sqcup$ : Parkin: a multipurpose neuroprotective agent? Neuron 2003, 38:13-16.

14. Jiang $H$, Ren $Y$, Zhao J, Feng J: Parkin protects human dopaminergic neuroblastoma cells against dopamine-induced apoptosis. Hum $\mathrm{Mol}$ Genet 2004, 13:1745-1754.

15. Masliah E, Rockenstein E, Veinbergs I, Mallory M, Hashimoto M, Takeda A Sagara Y, Sisk A, Mucke L: Dopaminergic loss and inclusion body formation in alpha-synuclein mice: implications for neurodegenerative disorders. Science 2000, 287:1265-1269.

16. von Coelln R, Dawson VL, Dawson TM: Parkin-associated Parkinson's disease. Cell Tissue Res 2004, 318:175-184.

17. Henn IH, Bouman L, Schlehe JS, Schlierf A, Schramm JE, Wegener E, Nakaso K, Culmsee C, Berninger B, Krappmann D, et al: Parkin mediates neuroprotection through activation of IkappaB kinase/nuclear factorkappaB signaling. The Journal of neuroscience: the official journal of the Society for Neuroscience 2007, 27:1868-1878.

18. Johnson BN, Berger AK, Cortese GP, Lavoie MJ: The ubiquitin E3 ligase parkin regulates the proapoptotic function of Bax. Proc Natl Acad Sci U S A 2012, 109:6283-6288.

19. Alves Da Costa C, Checler F: Apoptosis in Parkinson's disease: is p53 the missing link between genetic and sporadic Parkinsonism? Cell Signal 2011, 23:963-968.

20. da Costa CA, Sunyach C, Giaime E, West A, Corti O, Brice A, Safe S, AbouSleiman PM, Wood NW, Takahashi H, et al: Transcriptional repression of p53 by parkin and impairment by mutations associated with autosomal recessive juvenile Parkinson's disease. Nat Cell Biol 2009, 11:1370-1375.

21. Gu Z, Nakamura T, Yao D, Shi ZQ, Lipton SA: Nitrosative and oxidative stress links dysfunctional ubiquitination to Parkinson's disease. Cell Death Differ 2005, 12:1202-1204.

22. Vance JM, Ali S, Bradley WG, Singer C, Di Monte DA: Gene-environment interactions in Parkinson's disease and other forms of parkinsonism. Neurotoxicology 2010, 31:598-602

23. Wang C, Ko HS, Thomas B, Tsang F, Chew KC, Tay SP, Ho MW, Lim TM, Soong TW, Pletnikova $\mathrm{O}$, et al: Stress-induced alterations in parkin solubility promote parkin aggregation and compromise parkin's protective function. Hum Mol Genet 2005, 14:3885-3897.

24. Chung KK, Thomas B, Li X, Pletnikova O, Troncoso JC, Marsh L, Dawson VL, Dawson TM: S-nitrosylation of parkin regulates ubiquitination and compromises parkin's protective function. Science 2004, 304:1328-1331.

25. Meng F, Yao D, Shi Y, Kabakoff J, Wu W, Reicher J, Ma Y, Moosmann B, Masliah E, Lipton SA, Gu Z: Oxidation of the cysteine-rich regions of parkin perturbs its E3 ligase activity and contributes to protein aggregation. Mol Neurodegener 2011, 6:34

26. Yao D, Gu Z, Nakamura T, Shi ZQ, Ma Y, Gaston B, Palmer LA, Rockenstein EM, Zhang Z, Masliah E, et al: Nitrosative stress linked to sporadic Parkinson's disease: S-nitrosylation of parkin regulates its E3 ubiquitin ligase activity. Proc Natl Acad Sci U S A 2004, 101:10810-10814.

27. Costello S, Cockburn M, Bronstein J, Zhang X, Ritz B: Parkinson's disease and residential exposure to maneb and paraquat from agricultural applications in the central valley of California. Am J Epidemio/ 2009, 169:919-926.

28. Liou HH, Tsai MC, Chen CJ, Jeng JS, Chang YC, Chen SY, Chen RC: Environmental risk factors and Parkinson's disease: a case-control study in Taiwan. Neurology 1997, 48:1583-1588.

29. Meco G, Bonifati V, Vanacore N, Fabrizio E: Parkinsonism after chronic exposure to the fungicide maneb (manganese ethylene-bis-dithiocarbamate) Scandinavian journal of work, environment \& health 1994, 20:301-305.

30. Cicchetti F, Lapointe N, Roberge-Tremblay A, Saint-Pierre M, Jimenez L, Ficke BW, Gross RE: Systemic exposure to paraquat and maneb models early Parkinson's disease in young adult rats. Neurobiol Dis 2005, 20:360-371

31. Thiruchelvam M, Brockel BJ, Richfield EK, Baggs RB, Cory-Slechta DA: Potentiated and preferential effects of combined paraquat and maneb on nigrostriatal dopamine systems: environmental risk factors for Parkinson's disease? Brain research 2000, 873:225-234.

32. Thiruchelvam M, Richfield EK, Baggs RB, Tank AW, Cory-Slechta DA: The nigrostriatal dopaminergic system as a preferential target of repeated exposures to combined paraquat and maneb: implications for Parkinson's disease. The Journal of neuroscience: the official journal of the Society for Neuroscience 2000, 20:9207-9214.

33. Thiruchelvam M, Richfield EK, Goodman BM, Baggs RB, Cory-Slechta DA: Developmental exposure to the pesticides paraquat and maneb and the Parkinson's disease phenotype. Neurotoxicology 2002, 23:621-633.

34. Zeevalk GD, Bernard LP, Guilford FT: Liposomal-glutathione provides maintenance of intracellular glutathione and neuroprotection in mesencephalic neuronal cells. Neurochem Res 2010, 35:1575-1587.

35. Desplats P, Patel P, Kosberg K, Mante M, Patrick C, Rockenstein E, Fujita M, Hashimoto M, Masliah E: Combined exposure to Maneb and Paraquat alters transcriptional regulation of neurogenesis-related genes in mice models of Parkinson's disease. Mol Neurodegener 2012, 7:49.

36. Hoglinger GU, Rizk P, Muriel MP, Duyckaerts C, Oertel WH, Caille I, Hirsch EC: Dopamine depletion impairs precursor cell proliferation in Parkinson disease. Nat Neurosci 2004, 7:726-735

37. Marxreiter F, Regensburger M, Winkler J: Adult neurogenesis in Parkinson's disease. Cellular and molecular life sciences: CMLS 2013, 70:459-473.

38. Duplan E, Sevalle J, Viotti J, Goiran T, Bauer C, Renbaum P, Levy-Lahad E, Gautier CA, Corti O, Leroudier N, et al: Parkin differently regulates presenilin-1 and presenilin-2 functions by direct control of their promoter transcription. Journal of molecular cell biology 2013, 5:132-142.

39. Zhang C, Lin M, Wu R, Wang X, Yang B, Levine AJ, Hu W, Feng Z: Parkin, a p53 target gene, mediates the role of p53 in glucose metabolism and the Warburg effect. Proc Natl Acad Sci U S A 2011, 108:16259-16264.

40. Viotti J, Duplan E, Caillava C, Condat J, Goiran T, Giordano C, Marie Y, Idbaih A, Delattre JY, Honnorat J, et al: Glioma tumor grade correlates with parkin depletion in mutant p53-linked tumors and results from loss of function of p53 transcriptional activity. Oncogene 2013. doi:10.1038/ onc.2013.124.

41. Imam SZ, Zhou Q, Yamamoto A, Valente AJ, Ali SF, Bains M, Roberts JL, Kahle PJ, Clark RA, Li S: Novel regulation of parkin function through c-Abl-mediated tyrosine phosphorylation: implications for Parkinson's disease. The Journal of neuroscience : the official journal of the Society for Neuroscience 2011, 31:157-163.

42. Duncan AJ, Heales SJ: Nitric oxide and neurological disorders. Mol Aspects Med 2005, 26:67-96.

43. Li X, Ye X, Li X, Sun X, Liang Q, Tao L, Kang X, Chen J: Salidroside protects against MPP(+)-induced apoptosis in PC12 cells by inhibiting the NO pathway. Brain Res 2011, 1382:9-18.

44. Singh S, Dikshit M: Apoptotic neuronal death in Parkinson's disease: involvement of nitric oxide. Brain Res Rev 2007, 54:233-250.

45. Zhang $L$, Dawson VL, Dawson TM: Role of nitric oxide in Parkinson's disease. Pharmacol Therapeut 2006, 109:33-41

46. Barthwal MK, Srivastava N, Shukla R, Nag D, Seth PK, Srimal RC, Dikshit M: Polymorphonuclear leukocyte nitrite content and antioxidant enzymes in Parkinson's disease patients. Acta neurologica Scandinavica 1999, 100:300-304.

47. Gatto EM, Riobo NA, Carreras MC, Chernavsky A, Rubio A, Satz ML, Poderoso $\mathrm{J}$ : Overexpression of neutrophil neuronal nitric oxide synthase in Parkinson's disease. Nitric oxide : biology and chemistry / official journal of the Nitric Oxide Society 2000, 4:534-539.

48. Singh S, Das T, Ravindran A, Chaturvedi RK, Shukla Y, Agarwal AK, Dikshit M: Involvement of nitric oxide in neurodegeneration: a study on the experimental models of Parkinson's disease. Redox report communications in free radical research 2005, 10:103-109.

49. Jenner P, Olanow CW: Understanding cell death in Parkinson's disease. Ann Neurol 1998, 44:S72-84.

50. Packer MA, Stasiv Y, Benraiss A, Chmielnicki E, Grinberg A, Westphal H, Goldman SA, Enikolopov G: Nitric oxide negatively regulates mammalian adult neurogenesis. Proc Natl Acad Sci U S A 2003, 100:9566-9571.

51. Zhu XJ, Hua Y, Jiang J, Zhou QG, Luo CX, Han X, Lu YM, Zhu DY: Neuronal nitric oxide synthase-derived nitric oxide inhibits neurogenesis in the adult dentate gyrus by down-regulating cyclic AMP response element binding protein phosphorylation. Neuroscience 2006, 141:827-836.

52. Brune B, von Knethen A, Sandau KB: Transcription factors p53 and HIF-1alpha as targets of nitric oxide. Cell Signal 2001, 13:525-533. 
53. Calmels $\mathrm{S}$, Hainaut $\mathrm{P}$, Ohshima $\mathrm{H}$ : Nitric oxide induces conformational and functional modifications of wild-type p53 tumor suppressor protein. Cancer research 1997, 57:3365-3369.

54. Hess DT, Matsumoto A, Kim SO, Marshall HE, Stamler JS: Protein S-nitrosylation: purview and parameters. Nat Rev Mol Cell Bio 2005, 6:150-166.

55. Schonhoff CM, Daou MC, Jones SN, Schiffer CA, Ross AH: Nitric oxidemediated inhibition of Hdm2-p53 binding. Biochemistry 2002, 41:13570-13574.

56. Williams JL, Ji P, Ouyang N, Kopelovich L, Rigas B: Protein nitration and nitrosylation by NO-donating aspirin in colon cancer cells: Relevance to its mechanism of action. Exp Cell Res 2011, 317:1359-1367.

57. Blum D, Wu Y, Nissou MF, Arnaud S, Alim Louis B, Verna JM: p53 and Bax activation in 6-hydroxydopamine-induced apoptosis in PC12 cells. Brain research 1997, 751:139-142

58. Mandir AS, Simbulan-Rosenthal CM, Poitras MF, Lumpkin JR, Dawson VL, Smulson ME, Dawson TM: A novel in vivo post-translational modification of $\mathrm{p} 53$ by PARP-1 in MPTP-induced parkinsonism. Journal of neurochemistry 2002, 83:186-192.

59. Nair VD: Activation of p53 signaling initiates apoptotic death in a cellular model of Parkinson's disease. Apoptosis : an international journal on programmed cell death 2006, 11:955-966.

60. Morrison RS, Kinoshita Y: The role of p53 in neuronal cell death. Cell death and differentiation 2000, 7:868-879.

61. Duan W, Zhu X, Ladenheim B, Yu QS, Guo Z, Oyler J, Cutler RG, Cadet JL, Greig NH, Mattson MP: p53 inhibitors preserve dopamine neurons and motor function in experimental parkinsonism. Annals of neurology 2002, 52:597-606.

62. Toggas SM, Masliah E, Rockenstein EM, Rall GF, Abraham CR, Mucke L: Central nervous system damage produced by expression of the HIV-1 coat protein gp120 in transgenic mice. Nature 1994, 367:188-193.

63. Gil-Perotin S, Marin-Husstege M, Li J, Soriano-Navarro M, Zindy F, Roussel MF, Garcia-Verdugo JM, Casaccia-Bonnefil P: Loss of p53 induces changes in the behavior of subventricular zone cells: implication for the genesis of glial tumors. The Journal of neuroscience : the official journal of the Society for Neuroscience 2006, 26:1107-1116.

64. De la Monte SM, Sohn YK, Ganju N, Wands JR: P53- and CD95-associated apoptosis in neurodegenerative diseases. Laboratory investigation; a journal of technical methods and pathology 1998, 78:401-411.

65. Mogi M, Kondo T, Mizuno Y, Nagatsu T: p53 protein, interferon-gamma, and NF-kappaB levels are elevated in the parkinsonian brain. Neuroscience letters 2007, 414:94-97.

66. Norris EH, Uryu K, Leight S, Giasson BI, Trojanowski JQ, Lee VM: Pesticide exposure exacerbates alpha-synucleinopathy in an A53T transgenic mouse model. The American journal of pathology 2007, 170:658-666.

67. Mucke L, Abraham CR, Ruppe MD, Rockenstein EM, Toggas SM, Mallory M, Alford M, Masliah E: Protection against HIV-1 gp120-induced brain damage by neuronal expression of human amyloid precursor protein. The Journal of experimental medicine 1995, 181:1551-1556.

68. Jaffrey SR, Erdjument-Bromage H, Ferris CD, Tempst P, Snyder SH: Protein S-nitrosylation: a physiological signal for neuronal nitric oxide. Nature cell biology 2001, 3:193-197.

69. Uehara T, Nakamura T, Yao D, Shi ZQ, Gu Z, Ma Y, Masliah E, Nomura Y, Lipton SA: S-nitrosylated protein-disulphide isomerase links protein misfolding to neurodegeneration. Nature 2006, 441:513-517.

70. Eckardt-Michel J, Lorek M, Baxmann D, Grunwald T, Keil GM, Zimmer G: The fusion protein of respiratory syncytial virus triggers $\mathrm{p} 53$-dependent apoptosis. Journal of virology 2008, 82:3236-3249.

71. Louis M, Zanou N, Van Schoor M, Gailly P: TRPC1 regulates skeletal myoblast migration and differentiation. Journal of cell science 2008, 121:3951-3959.

doi:10.1186/1750-1326-8-29

Cite this article as: Sunico et al: S-Nitrosylation of parkin as a novel regulator of $\mathrm{p} 53$-mediated neuronal cell death in sporadic Parkinson's disease. Molecular Neurodegeneration 2013 8:29.

\section{Submit your next manuscript to BioMed Central and take full advantage of:}

- Convenient online submission

- Thorough peer review

- No space constraints or color figure charges

- Immediate publication on acceptance

- Inclusion in PubMed, CAS, Scopus and Google Scholar

- Research which is freely available for redistribution

Submit your manuscript at www.biomedcentral.com/submit
C Biomed Central 